https://doi.org/10.31426/ijamsr.2018.1.4.211

International Journal of

I J A M S R

Advanced Multidisciplinary Scientific Research (IJAMSR) ISSN:2581-4281

\title{
EFFECTIVENESS OF EXPLICIT INSTRUCTION OF COHESIVE DEVICES ON IRANIAN EFL LEARNERS' WRITING DEVELOPMENT
}

\section{Hossein Kargar Behbahani ${ }^{1}$ Ali Akbar Jabbari², Amir Hamed Dolatabadi Farahani ${ }^{3}$}

M.A.in TEFL Yazd University, Iran

Associate Professor of English, Department of English, Yazd University, Iran,

M.A.in English Literature, Payam-e- Noor University, Iran

hossein_july1993@yahoo.com

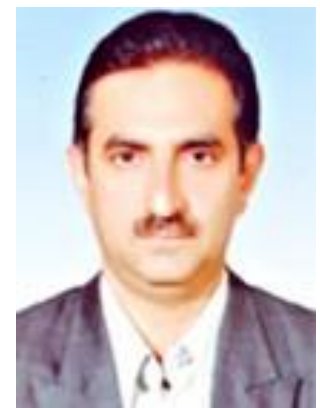

Dr.ALI AKBAR JABBARI

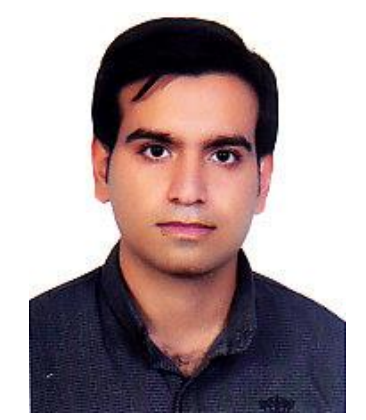

HOSSEIN KARGAR BEHBAHANI

Keywords: Cohesion, Coherence, Writing, Discourse, Unity.

\begin{abstract}
A B S T R A C T
The present study aims to investigate the effect of explicit instruction of cohesion and coherence in Iranian EFL learners' writing development. Cohesion and coherence are both important concepts which cover a large number of discourse features of texts that need to be mastered by language learners. The aim, then, is to determine whether the students' writing ability would be improved when teachers explicitly teach these ideas in their classes. In order to achieve the aims, the described methodology has been used. The sample has been randomly chosen from students of English at university level. The results of the Independent-sample T-tests administered showed that for both males and females, the explicit group outperformed the control group and also the higher the proficiency of learners, the better their writing ability. The implication of the study is that ESL/EFL teachers can implement explicit instruction of cohesion and coherence to better teach their students how to write a coherent piece of discourse.
\end{abstract}

Citation: Hossein Kargar Behbahani, Ali Akbar Jabbari, Amir Hamed Dolatabadi Farahani (2018). Effectiveness Of Explicit Instruction Of Cohesive Devices On Iranian Efl Learners' Writing Development. International Journal of Advanced Multidisciplinary Scientific Research (IJAMSR) ISSN:2581-4281 Vol 1, Issue 4,June, 2018, \#Art.211, pp1-10

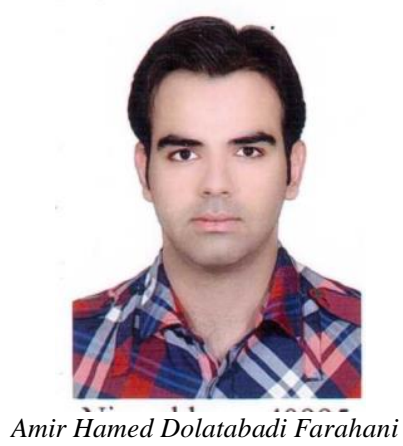




\section{International Journal of Advanced Multidisciplinary Scientific Research (IJAMSR) ISSN:2581-4281}

\section{Introduction}

The nature of second language writing (L2) has become clearer nowadays. Broadly speaking, we may say that research conducted in the areas of linguistics, psycholinguistics, cognitive psychology, and sociolinguistics has helped us to gain a better understanding of how the ability to write is likely to be learnt. We are now aware that writing is not a decontextualized activity, but rather it is embedded in the cultural and institutional context in which it is produced (Kern, 2000; Hyland, 2002). Additionally, it involves a dynamic interaction among the three basic elements that play a part in the writing act, namely the text, the writer, and the reader, which require writers' consideration of all them in order to write accordingly (Silva \& Matsuda, 2002). Needless to say, this view of writing has affected its teaching. In particular, it has stressed the key role that the social and contextual factors play in creating a piece of written discourse.

Unarguably, writing has always been regarded as a challenging task for EFL learners as it requires them not only to be aware of English structure, but also to get more information about the properties of English text (Wahby, 2014). Writing is an important means of communication, especially in academic communities. Students keep written records of lectures, do written homework, and write summaries and reports. So, as we access those EFL students on the basis of their writing mastery, we have to consider that writing has two perspectives: the structural and the communicative. Widdowson (2001) distinguishes between writing as usage and writing as use. He defines the former as "... the use of the visual medium to manifest the graphological and the grammatical system of the language", and the latter as "the use of sentences to build discourse". It is also worth mentioning that any study of language above the sentence is called discourse analysis. Chiang (1993, 2003) verifies that native speakers' judgments of the quality of EFL students' writing rely more on discourse features like cohesion and coherence. Grammatical weaknesses are not counted unless they hinder their understandings of the writer's intended meaning. However, the majority of ESL/EFL students feel that "their only sense of security comes from what they have learnt from grammar" (Leki, 1996: 34). Hence, one of the major objectives of the current study is to see to what extent Iranian EFL learners can use the ideas of cohesion in their compositions as a writing task.

Truly, students look at writing as an arduous task. According to Richards \& Renandya (2002) the difficulty emanates both from generating and organizing ideas and translating these ideas into readable text. Halliday and Hasan (1976) believed that cohesion and coherence, as the two important textual elements have long been recognized as important features of good writing. So, language learners indispensably need to write coherent, cohesive texts if they wish to prove to be qualified English writers, whether they are EFL or ESL writers.

A text is considered not to be a unit of syntax, but a unit of semantics. According to Halliday and Hasan (1976), the context of texture displays the feature of being a text. It is obvious that all languages have texts and so do certain linguistic features that create texture. Therefore, it can be concluded that any texture is made up of two distinct and different levels: the sequence and the textual. Also, it should be reminded that the fundamental building blocks from which all texts are constructed are four independent components on the two aforementioned levels. The sequential level, on the one hand, is 


\section{International Journal of Advanced Multidisciplinary Scientific Research (IJAMSR) ISSN:2581-4281}

grammatical features of syntax at surface level representing semantics at deep structure. On the sentential level are syntax and semantics. Syntactic components involve types of phrasing, types of clause construction, types of passive structures, clausal combinations, and word order within a sentence. Semantic components involve the senses and mappings from word meanings of sentential meaning.

On the textual level, on the other hand, is functional features of cohesion at surface level leading to coherence at deep structure. Grabe and Kaplan (1996) believed that cohesion and coherence are on the textual level. This level is at the underlying structure of the surface structure achieved through the use of grammatical elements to form the sentences and the first stage in the formation of the text through cohesion and coherence constructed on the basis of the textual cohesion through the readers' efforts to interpret.

Considering the fact that, to the best of my knowledge, only few studies have considered the importance and effectiveness of the explicit instruction of cohesive devices in the development of Iranian EFL learners, I think there is still room for further research to shed more light on the effect of explicit instruction of cohesive ties. The main objective of this paper is to see to what extent Iranian EFL learners majoring in English Literature or Translation benefit from this kind of explicit teaching.

This subject arose from my interest to investigate whether explicit knowledge of cohesive devices affects Iranian EFL learners' writing or not. To me, because a chapter of The Study of Language by Yule is devoted to cohesion and coherence, those who has passed this course can write a unified piece of discourse far better than those Iranian EFL learners who are not yet familiar with the ideas of cohesion and coherence.

\section{Review of Related Literature}

Although much has been written about cohesion, the basic definitions and categories need to be reviewed because of their pertinence to my point. At the local level a discourse is coherent if there are semantic relationships between successive sentences. A central concept is the notion of cohesion. Halliday and Hasan (1976) define cohesion as referring to "the range of possibilities that exist of linking something with what has gone before" (p. 10). They also studied categories of cohesion to be discussed below.

One type of cohesion is called a reference. Reference is a semantic relation whereby information needed for the interpretation of one item is found elsewhere in the text. We often use pronouns such as she, he, it, his, her, and there to refer to their earlier points. We also use demonstratives such as the, this, that, and those for referential purposes. Another type of reference is a comparative reference in which we use terms such as same, different, and similar to relate current objects with those in the past.

Halliday and Hasan identify several other categories of cohesion. In substitution, we replace one lexical item with another as an alternative to repeating the first. Ellipsis is a form of cohesion that is really a special case of substitution in which we "substitute" one phrase with nothing. In conjunctive cohesion, we express a relationship between phrases or sentences by using conjunctions such as and, or, but, yet, and so. In Lexical cohesion, a tie is made between one sentence or phrase and another by virtue of the lexical relationships between certain words in the sentence. In the simplest 


\section{International Journal of} Advanced Multidisciplinary Scientific Research (IJAMSR) ISSN:2581-4281

instance, we merely reiterate the same word used earlier. Other forms of lexical cohesion may be based on relationships such as synonymy and hyponymy.

As can be inferred from above, cohesion consists of relating some current expression to one encountered earlier. This is called anaphoric reference. When we use an expression to refer back to something previously mentioned in the discourse, the referring expression is called an anaphor, and the previous referent is called an antecedent. Alternatively, we sometimes use referring expression to point forward, which is called cataphoric reference.

According to Carroll (2007) of all these forms of cohesion, anaphoric reference has commanded the greatest interest among psycholinguists. One reason is that anaphoric reference enables us to explore the role of working memory in discourse comprehension. To understand a simple pair of sentences, we must hold the antecedent is working memory long enough to link it with the anaphor (p. 161).

Unfortunately, most language teachers consider that the mere appearance of cohesive devices in the text should contribute to the quality of text. Besides, it has been noted that traditionally in English, ESL writing research teachers primarily focus on low level features in student writing rather than discourse features in their teaching of writing (Lee, 1998). On the other hand, Crowhurst (1983) and McCulley (1985) state that the use of certain linguistic devices is related to differences in the quality of student persuasive writing. On the other hand, Grake \& Kaplan (1996) and Ferris \& Hedgecock (1998), in their study, consider that EFL students tend to focus on word and sentence levels rather than discourse such as the organization of texts. Their study also suggests that nonnative subjects have more trouble linking up parts of sentences, linking sentences with other sentences, and linking paragraphs with other paragraphs. Thus, it seems that studying the relationship between students' cohesive knowledge and their errors in using cohesive devices in their writing has pedagogical significance. This paper aims to investigate how far explicit instruction of cohesive ties can lead to the development of Iranian EFL learners. More specifically, the study addresses the following research questions:

1. Is there any significant difference between experimental and control group across gender?

2. Is there any significant difference between experimental and control group across proficiency?

\section{Method}

\section{Participants}

Participants of the current study were $60 \mathrm{BA}$ students majoring in English Language and English Translation. 30 students were male and the rest were female. These students were divided into two groups namely, experimental and control group. Those receiving explicit instructions of cohesive devices were named experimental and those receiving no instruction in this regard were labeled as a control group. Besides, based on the scores they got from the Oxford Quick Placement Test, the subjects were divided into two groups according to their proficiency level. Please note the following table. 
Table1. Proficiency

\begin{tabular}{|l|l|}
\hline Proficiency & $\begin{array}{l}\text { Oxford Quick Placement Test } \\
\text { range }\end{array}$ \\
\hline Lower Intermediate & $28-36$ \\
\hline Upper Intermediate & $39-40$ \\
\hline
\end{tabular}

\section{Instrument}

The instruments for the current study were an Oxford Quick Placement Test and a test to examine the students' writings. It is worth mentioning that the Oxford Quick Placement Test was administered to see the proficiency level of the subjects.

\section{Procedure}

As mentioned above, the researcher's aim was to investigate whether explicit instruction of the ideas of cohesion and coherence can result in better development of Iranian EFL learners' writing. To this end, the participants were divided into two groups of experimental and control groups (each 30). Then, the experimental group received 4 sessions of teaching. Each session lasted for 30 minutes. In the first session, the participants were provided with the ideas of cohesion and coherence namely, their definitions and their subcategories based on the works of Halliday and Hasan (1976). In the second, third and fourth sessions they were provided with some exercises to practice what they have learned in the first session. At the exam session, the students were required to write a composition about a well-known person they know about.

\section{Results}

Addressing the first research question:
In the first research question we have an independent variable, namely group having two levels (experimental and control) and a dependent variable (score). So, in this case, the use of Independent-samples T-test is warranted.

First, I ran a one-sample Kolmogrov-Smirnov Test to see whether the normality assumption underlying this kind of T-test is met or not.

Table 2. One-Sample Kolmogorov-Smirnov Test

\begin{tabular}{|l|l|r|}
\hline \multicolumn{2}{|l|}{} & \multicolumn{1}{c|}{ Score } \\
\hline \multirow{2}{*}{ Normal Parameters ${ }^{\text {b,c }}$} & Mean & 30 \\
\cline { 2 - 3 } & Std. Deviation & 2.74799 \\
\hline \multirow{3}{*}{ Most Extreme Differences } & Absolute & .100 \\
\cline { 2 - 3 } & Positive & .079 \\
\cline { 2 - 3 } & Negative & -.100 \\
\hline Kolmogorov-Smirnov Z & & .548 \\
\hline Asymp. Sig. (2-tailed) & .925 \\
\hline $\begin{array}{l}\mid \\
\text { a. gender = male }\end{array}$ \\
\hline $\begin{array}{l}\mid \\
\text { b. Test distribution is Normal. }\end{array}$ \\
\hline c. Calculated from data. \\
\hline
\end{tabular}

Table 3. One-Sample Kolmogorov-Smirnov Test

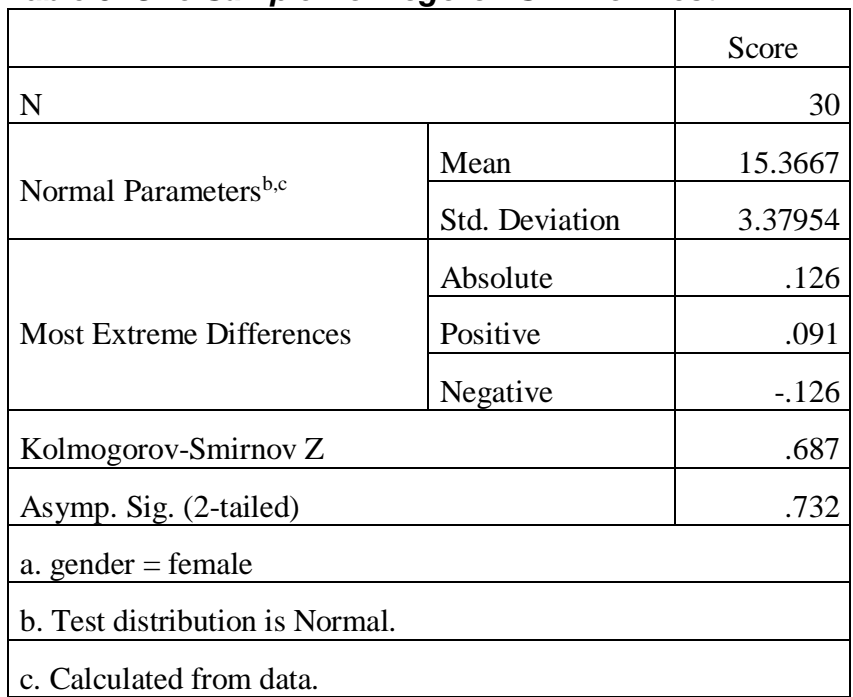

The results obtained from the above tables

display that the normality assumption is met. 
https://doi.org/10.31426/ijamsr.2018.1.4.211

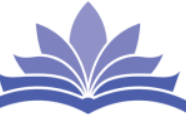

I J A M S R

International Journal of

Advanced Multidisciplinary Scientific Research (IJAMSR) ISSN:2581-4281

Table 4. Group Statistics

\begin{tabular}{|c|c|c|c|c|c|}
\hline & Group & $\mathrm{N}$ & Mean & $\begin{array}{c}\text { Std. } \\
\text { Deviatio } \\
\mathrm{n}\end{array}$ & $\begin{array}{l}\text { Std. } \\
\text { Error } \\
\text { Mean }\end{array}$ \\
\hline Sco & $\begin{array}{l}\text { Experim } \\
\text { ental }\end{array}$ & 15 & $\begin{array}{r}17.66 \\
67 \\
\end{array}$ & 1.77197 & .45752 \\
\hline re & control & 15 & $\begin{array}{r}13.96 \\
67\end{array}$ & 2.27342 & .58700 \\
\hline
\end{tabular}

Table 5. Group Statistics

\begin{tabular}{|l|l|r|r|r|c|}
\hline & Group & $\mathrm{N}$ & Mean & $\begin{array}{c}\text { Std. } \\
\text { Deviation }\end{array}$ & $\begin{array}{c}\text { Std. Error } \\
\text { Mean }\end{array}$ \\
\hline \multirow{2}{*}{$\begin{array}{l}\text { sco } \\
\text { re }\end{array}$} & $\begin{array}{l}\text { Experim } \\
\text { ental }\end{array}$ & 15 & $\begin{array}{r}17.56 \\
67\end{array}$ & 2.54507 & .65713 \\
\cline { 2 - 6 } & control & 15 & 13.16 & 2.60951 & .67377 \\
67 & & \\
\hline \multicolumn{4}{|l}{ a. gender = female } \\
\hline
\end{tabular}

The results of tables 4 and 5 show that the mean for both males and females in the experimental group is very close to each other (17.66 and 17.56 respectively). Also the mean for both males and females in the control group is very close to each other (13.96 and 13.16 respectively).
Table 6. Independent Samples Test

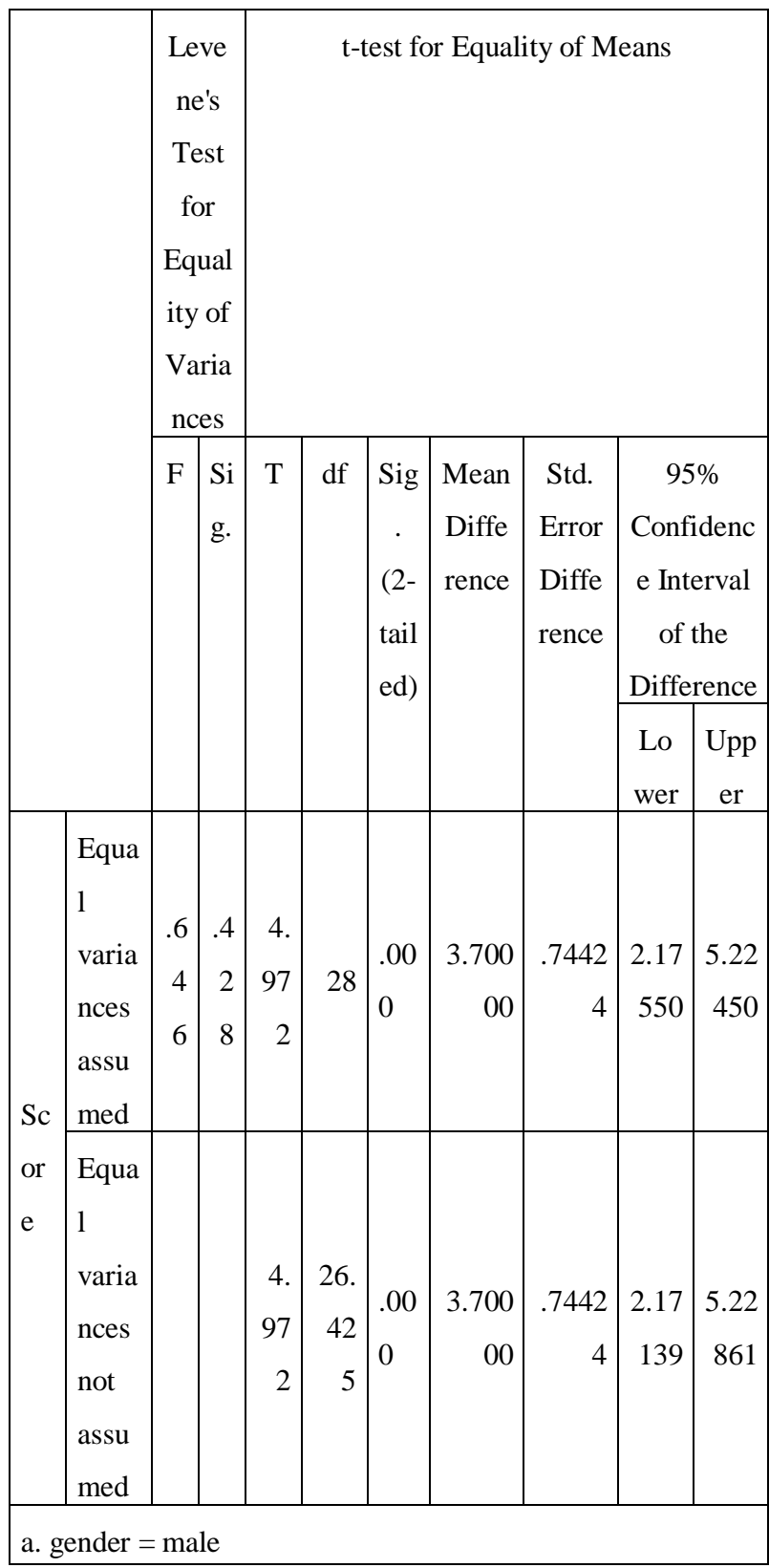

For males. Because the sig. value in the Levene's Test for Equality of Variances is above $0.05(\mathrm{Sig} .=.428)$, the homogeneity assumption is not met. So, the sig. (2tailed) value at the Equal variances not assumed should 
https://doi.org/10.31426/ijamsr.2018.1.4.211

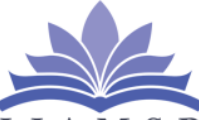

I J A M S R

\section{International Journal of}

Advanced Multidisciplinary Scientific Research (IJAMSR) ISSN:2581-4281

be looked at. The $p$ value here is less than 0.05 ( $p=0.001)$ indicating a statistically significant difference between the two groups of males. Besides, using the Etasquared formula, the obtained value is. 32 . According to Cohen (1988) this obtained result shows a large effect size.

Table 7. Independent Samples Test

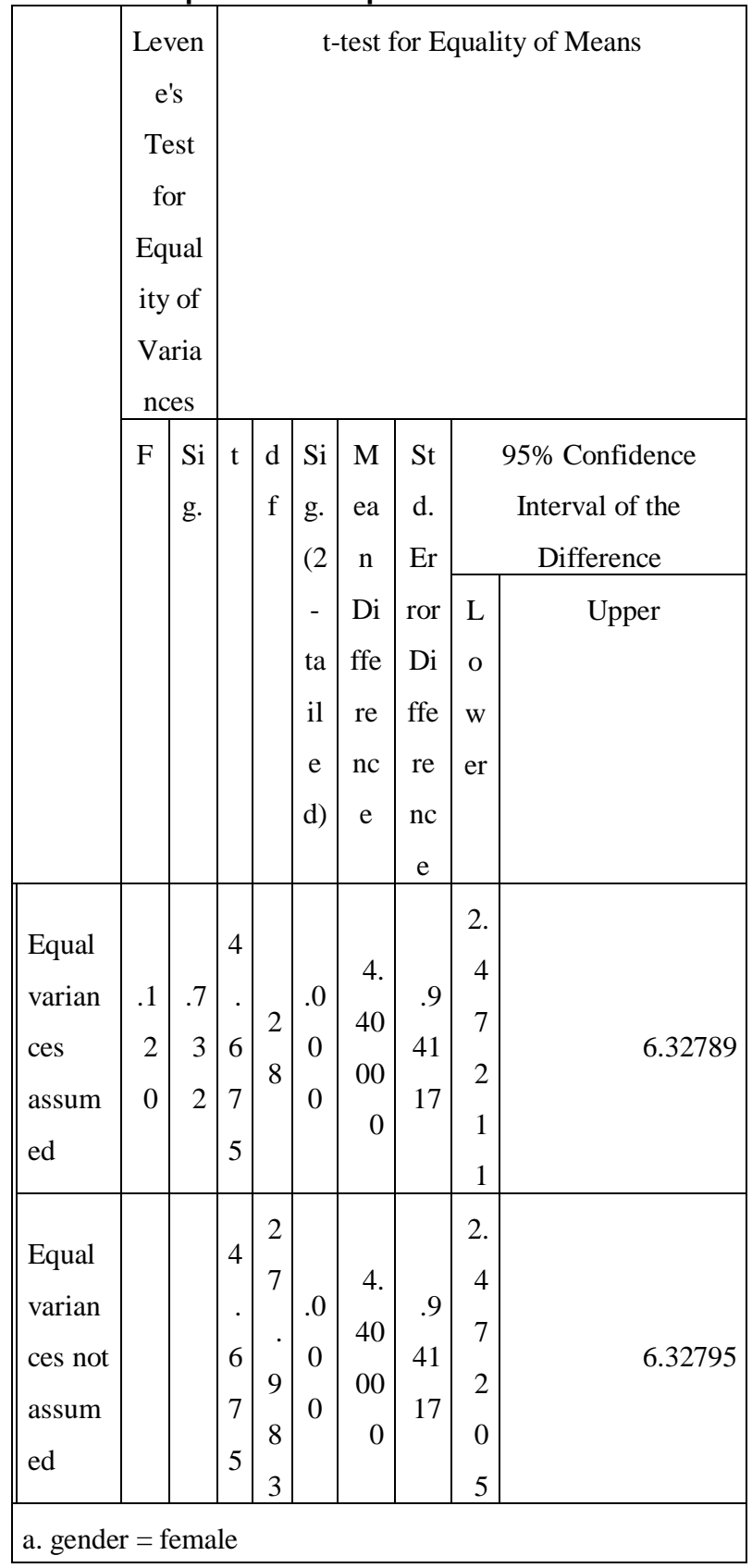

For females, again, because the sig. value in the Levene's Test for Equality if Variances is above .05 (sig. $=.732$ ), the homogeneity assumption is not met either. Consequently, the sig. (2-tailed) value at the Equal variances not assumed should be considered. The $p$ value here is less than 0.05 demonstrating a statistically significant difference between the two groups of females. Additionally, using Eta-squared formula, the obtained value is .43 . Thus, as Cohen puts it, the result shows a large effect size as well.

\section{Addressing The Second Research Question}

Firstly, a one-sample Kolmogrov-Smirnov Test was conducted to see whether the normality assumption is met.

Table 8. One-Sample Kolmogorov-Smirnov Test

\begin{tabular}{|l|l|r|}
\hline \multicolumn{2}{|l|}{} & Proficiency \\
\hline \multirow{2}{*}{ Normal Parameters ${ }^{\mathrm{b}, \mathrm{c}}$} & Mean & 30 \\
\cline { 2 - 3 } & Std. Deviation & $.00000^{\mathrm{d}}$ \\
\hline a. Proficiency = upper & \\
\hline \multicolumn{2}{|l|}{ b. Test distribution is Normal. } \\
\hline
\end{tabular}

Table 9. One-Sample Kolmogorov-Smirnov Test

\begin{tabular}{|l|l|r|}
\hline \multicolumn{2}{|l|}{} & Proficiency \\
\hline $\mathrm{N}$ & 30 \\
\hline \multirow{2}{*}{ Normal Parameters $^{\mathrm{b}, \mathrm{c}}$} & Mean & 2.0000 \\
\cline { 2 - 3 } & Std. Deviation & $.00000^{\mathrm{d}}$ \\
\hline
\end{tabular}

a. proficiency $=$ lower

b. Test distribution is Normal.

Considering the above tables, the normality assumption is satisfied. 
https://doi.org/10.31426/ijamsr.2018.1.4.211

\section{International Journal of} Advanced Multidisciplinary Scientific Research (IJAMSR) ISSN:2581-4281

Table 10. Group Statistics

\begin{tabular}{|l|l|r|r|c|c|}
\hline & $\begin{array}{l}\text { Profici } \\
\text { ency }\end{array}$ & $\mathrm{N}$ & Mean & $\begin{array}{c}\text { Std. } \\
\text { Deviation }\end{array}$ & $\begin{array}{c}\text { Std. Error } \\
\text { Mean }\end{array}$ \\
\hline \multirow{3}{*}{ scores } & Upper & 30 & 17.091 & 2.02089 & .36896 \\
\cline { 2 - 6 } & lower & 30 & 13.875 & 2.61441 & .47732 \\
\hline
\end{tabular}

The results of the table 10 shows that the mean for upper-intermediate group is 17.07 and that of the lower intermediate group is 13.87 indicating that those subjects in upper-intermediate group outperformed lowerintermediate group.
Table 11. Independent Samples Test

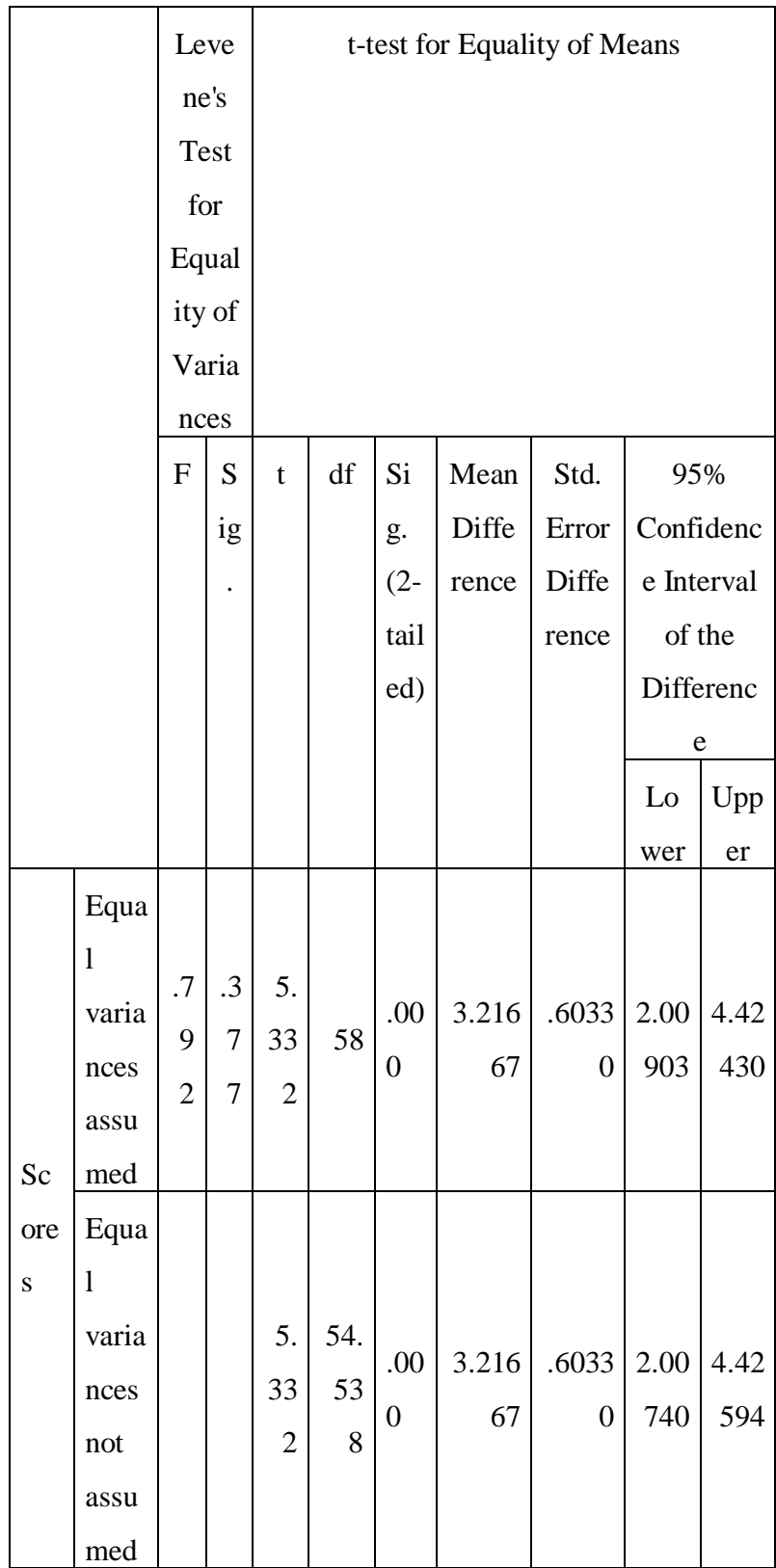




\section{International Journal of Advanced Multidisciplinary Scientific Research (IJAMSR) ISSN:2581-4281}

Considering table 11, because the sig. value in the Levene's Test for Equality of Variances is above 0.05 ( $p=.377)$, the homogeneity assumption is violated, thus we need to consider the row in Equal variances not assumed. Here because the alpha value is less than 0.05 ( $p=0.001$ ), we can see that the difference between the two groups in terms of proficiency is statistically significant. To examine to effect size of this significant difference, eta squared formula was used. The obtained value is.32 which is a large effect size based on Cohen's (1988) interpretation. All in all, the results show that the more proficient one is, the better he/she can write.

\section{Discussion}

The results of the current study showed and proved that not only is there a significant difference between the experimental and control groups across gender, but also there is a significant difference between lowerintermediate and upper-intermediate groups in terms of the unity of their writing. In the section addressing the first research question, I explained why there is a significant difference between the two groups. The results of the tables given in that section display the significance of explicit instruction of cohesion and coherence. The more Iranian EFL students are explicitly aware of the ideas of cohesion and coherence, the more appropriate is their writings. This result is compatible and in line with that of Wahby (2013) who found a significant correlation between the teaching of cohesive ties and Arabic EFL learners' use. Moreover, the researcher tried to have the same number of males and females at the time of gathering data, in fact, this confounding variable was controlled in order to see whether the findings can be in line with that of Wahby or not. Having considered above tables and explanations, we can see that not only is there a significant difference between the two groups for male, but also there is a statistically significant difference between the two groups of females. Thus, it is safe to say that explicit knowledge of the ideas of cohesion and coherence can help one to write a coherent text and that only tacit knowledge e.g. implicit knowledge of cohesion and coherence alone cannot be enough. This is also compatible of Clahsen \& Felser (2006) who found that language cannot be reduced to procedural memory e.g. implicit memory. To fully learn a language, we need to be explicitly aware of what we are going to learn.

With respect to the second research question, in the section addressing the second research question, I showed that there is a statistically significant difference between upper-intermediate and lower-intermediate groups in terms of proficiency. There I showed that the more proficient one is, the better he/she can write. Thus, proficiency is a very useful tool to predict the extent to which one can provide the reader with a coherent text. With respect to the second research question, the researcher, again, attempted to control the confounding variable, namely, proficiency by having the same of a number of lower-intermediate and upper-intermediate subjects. Having considered above tables and explanations, we can readily understand that there is a large effect size for proficiency that is proficiency can surely play a role in the extent to which one can write a coherent piece of text. The more one's proficiency, the more our expectations can be with him/her to provide us with a coherent text. 


\section{Implications of the study}

The present study, based on the findings and discussions illustrated above, provided some suggestions for both ESL/EFL teachers and ESL/EFL learners. First of all, with respect to the first research question, we can safely say that explicit instruction of cohesion and coherence can result in better development of Iranian EFL learners. So, ESL/EFL teachers wanting to train their students to write a coherent piece of discourse can implement this section into their classes, most significantly the subcategories provided by Halliday and Hasan (1976) given above.

Second, with respect to the second research question, teachers can expect more of the proficient learners to write a coherent text. With respect to less proficient ESL/EFL learners, they can be less strict. This does not mean for the EFL/ESL teacher not to expect a less proficient learner to write a unified and coherent piece of discourse at all, but the researcher suggests that as the student gets more proficient in L2, the teacher can expect more and more for him/her to write a unified and coherent piece of text. A less proficient ESL/EFL learner can reduce the gap between himself/herself and the more proficient learner by practicing cohesive devices more and more. This way, he/she can reduce the gap and provide the reader with a more unified and coherent text.

\section{Limitations of the study}

The internal validity of the study, as far as less proficient learners are concerned, might be affected by L1 interference. Some students, despite having good cohesive knowledge, might have applied their knowledge of cohesive devices in L1 to L2 (negative transfer). This might be the reason behind some repeated errors.

\section{Conclusion}

This study was conducted to examine the effectiveness of explicit instruction of the ideas of cohesion and coherence in Iranian EFL learners' writing development. The results of the first Independent-samples T-test displayed that the experimental group outperformed the control group showing the effectiveness of explicit instruction of cohesive devices. Besides, the results of the second Independent-samples T-test demonstrated that there is a significant difference between subjects in terms of proficiency indicating that the more proficiency of a learner is, the better can he/she write a unified and coherent text. Thus, ESL/EFL teachers, at least as far as writing is concerned, should explicitly teach the ideas of cohesion and coherence to their students so that they can write a more unified and coherent text.

\section{References}

1) Carroll, D. (2007). Psychology of Language: fifth edition, Tehran Rahnema publication, P.161.

2) Clahsen, H. \& Felser, C. (2006). Grammatical processing in language learners. Applied Psycholinguistics, 27, 3-42.

3) Crowhurst, M. (1983). Cohesion in argument and narration at 3 grade levels. Research in the teaching of English. 21: 185-201.

4) Ferris, D. \& Hedgecock, J. (1998). Teaching ESL composition : Purpose, Process and Practice. Mahwah, NJ: Lawrence ERBaum.

5) Grake, W. \& Kaplan, $R$ (1996). Writing in a second language contrastive rhetoric.

6) Halliday, M. \& Hasan, R. (1976). Cohesion in English, London: Longman.

7) Lee, I. (2002). Teaching coherence to ESL students. A Classroom Inquiry. Journal of Second Language Writing, 11, 135.159.

8) Richards, J. \& Renandya, W. (2002). Methodology in language teaching: An anthology of current practice. Cambridge: Cambridge University Press.

9) Wahby, M. (2014). The effect of implementing cohesive ties by Saudi prep-year pre intermediate students on their written texts. European Scientific Journal, 10.

10) Widdowson, H. (2000). On the limitations of linguistics applied. Applied Linguistics 21/1: 3-25. 